\title{
Rotating Brush Seal
}

\author{
S. B. LATTIME ${ }^{1, *}$, M. J. BRAUN ${ }^{2, \dagger, \ddagger}$, F. K. CHOY ${ }^{1, \ddagger}$, \\ R. C. HENDRICKS ${ }^{1}$, and B. M. STEINETZ ${ }^{1}$ \\ ${ }^{1}$ NASA Lewis Research Center, Cleveland, Ohio, USA; \\ ${ }^{2}$ Department of Mechanical Engineering, University of Akron, Akron, Ohio, USA
}

The proven technology of brush seals has been extended to the mitigation of problems arising from friction and wear at the bristle-rotor interface at high surface speeds. In prototype testing, the brush is mounted on, and free to rotate with the shaft, thus providing a compliant primary seal. A face seal positioned between the backing plate of the brush seal and the housing provides a secondary seal. The purpose of this paper is to demonstrate the interaction between the brush bristles and the shaft at high surface speeds as well as introduce a numerical model to simulate the bristle behavior.

A test facility was constructed to study the effects of centrifugal forces on bristle deflection in a single rotating brush seal. The bristle-rotor interface was observed through a video camera, which utilized a high magnification borescope and a high frequency strobe light source. Rotational speeds of the rotor and the brush seal were measured by magnetic and optical speed sensors, respectively. Preliminary results for speeds up to $11,000 \mathrm{rpm}$ show no speed differential between the brush seal and rotor, or any instability problems associated with the brush seal. Bristle liftoff from the rotor is successfully captured on video.

Keywords: Hybrid brush seal; Film riding face seal; Turbomachinery; Bristle wear; Thermal loads

Brush seals, due to their compliance characteristics, have become a rather serious competitor for replacement of their predecessors, the labyrinth seal, in gas turbine engines. Brush seals allow axial or radial excursions of the spool

Received 11 July 2001; In final form 13 July 2001.

* Formerly associated to B\&C Engineering Associates, Inc., Akron, $\mathrm{OH}$, USA

${ }^{\dagger}$ Corresponding author: Tel.: 330-972-7734, Fax: 330-972-6027. E-mail: mjbraun@uakron.edu

${ }^{\ddagger}$ Consultants to B\&C Engineering Associates, Inc., Akron, OH, USA shafts without suffering damage or affecting the sealing integrity. In 1988, Ferguson (1988) reported that over thousands of hours of testing, brush seal leakages were, on the average, $5-10 \%$ of those allowed by equivalently sized labyrinth seals. In 1991, Chupp et al. (1991) showed brush seal leakage reductions of 4.5 times that of labyrinth seals. Proctor et al. (1996) tested single and double sets of brush seals in liquid nitrogen and liquid hydrogen at speeds up to $65,000 \mathrm{rpm}$ and pressure drops up to 175 psid per brush. The authors found leakage rates for a single brush to be $1 / 3$ that of a 12-tooth labyrinth seal, and half that leakage rate when two brush seals, spaced about 0.25 inches apart, were used.

Although brush seals show a vast improvement in leakage performance over other seals, they can still be subject to catastrophic wear at the shaft/brush interface; that appears to be generated by excessive thermal loads borne by the friction due to the relative differential in sliding speeds. Much of the current literature on brush seals deals with the wear characteristics and material selection. In 1992, Atkinson and Bristol (1992) investigated bristle and rotor wear with two different bristle materials (cobalt and nickel based alloys) and three different coating materials (chromium carbide, tungsten carbide, and aluminum oxide). They found the brush wear to be temperature dependent. Hendricks et al. (1992) reported preliminary results of brush seal testing in the fourthstage turbine of the G.E. T-700 engine. Integrity testing of a brush seal in the shroud ring of a T-700 engine was also performed. The brush seal contained 0.0028 in. diameter bristles of Haynes 25, at a lay angle between 43 to $50^{\circ}$. The design clearance was 0.02 to 0.05 in. The turbine was operated at $10,000 \mathrm{rpm}$ and $850^{\circ} \mathrm{F}$ and at $20,000 \mathrm{rpm}$ and $1050^{\circ} \mathrm{F}$. Post test investigations showed regions of the brush seal where bristles had been pulled out and bentover near the inlet of the seal, snapped near the fence plate and a uniform smeared interface between the first and last axial rows. Forry (1993) tested wear characteristics for Inconel X-750 and Haynes 25 bristles, both with a 
chrome-carbide rotor journal coating. Both brush seals were run at $23,500 \mathrm{rpm}$ at approximately $900^{\circ} \mathrm{F}$ for 10 hours, and had an interference of about 0.03 in. with the rotor. Post test measurements indicated a wear of 0.033 in. for the X-750 bristles and 0.037 in. for the Haynes 25 bristles.

Generally, most of the activities related to the brush seal development have been experimental, with few notable exceptions. Thus, Braun et al. (1990) and Hendricks et al. (1991) offered a bulk flow model for flow through the body of a brush, based on analytical and experimental developments concerning flow in porous media. The analytical results, when compared with experimental data showed relatively good coincidence. The maximum differential in results was observed at low flows, and was approximately $30 \%$.

\section{THE CONCEPT OF THE HYBRID FLOATING BRUSH SEAL (HFBS)}

Attempting to utilize the improved leakage characteristics of brush seals for gas turbine applications, while eliminating the high relative surface speeds, Braun et al. (1995) and Braun and Choy (1996) have developed the concept of a hybrid brush seal which rotates with the shaft while its front and backing plates are riding against a non-contacting gas face seal. This arrangement is shown schematically in Figure 1. The figure depicts a longitudinal cross section through the seal test section. The rotating brush seal is situated inside a test chamber which it separates into high and low pressure sections, respectively. The brush is free to rotate with the shaft while seated in between two film riding face seals. The face seals act as secondary seals while providing dynamic stability and preventing the brush seal from axial travel with the rotor. This hybrid brush seal

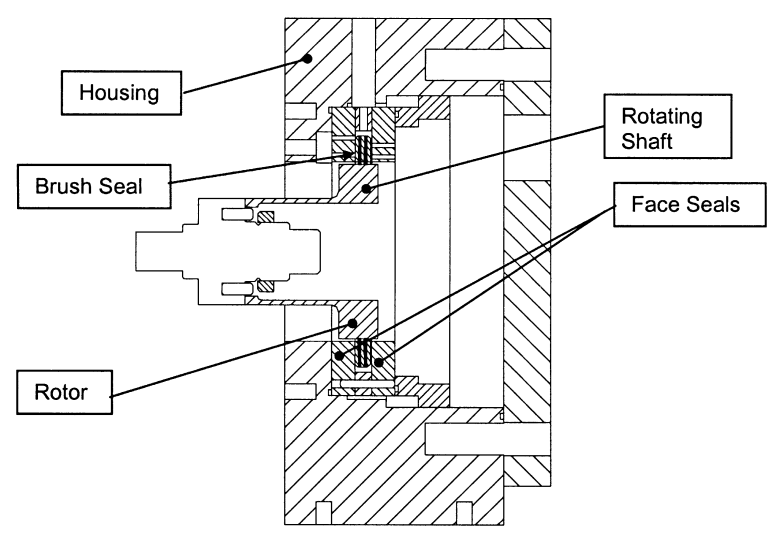

FIGURE 1 Cross section of hybrid brush seal assembly. concept was tested successfully in feasibility studies under a Phase 1 of a NASA SBIR award. The feasibility studies were run at rotor velocities of up to $5,000 \mathrm{rpm}$ and at room temperature. The second phase of this prototype development involved testing the seal configuration at speeds up to $40,000 \mathrm{rpm}$ and temperatures up to $900^{\circ} \mathrm{F}$, conditions that model actual engine conditions.

This paper presents some experimental preliminary results showing the effects of centrifugal forces on bristle displacement due to brush rotational velocities up to $11,000 \mathrm{rpm}$. An analytical predictive model based upon a simple, single beam deflection theory will be presented as well.

\section{EXPERIMENTAL APPARATUS}

The test rig is shown schematically in Figure 2. A steel shaft is supported at each end by ball bearings located in upright aluminum housings. The shaft is driven by a variable speed motor that is connected through a belt and pulley system. The pulley system allows the shaft to reach velocities as high as $15,000 \mathrm{rpm}$. The shaft's test rotor is stepped to different diameters allowing different pre-loads of the brush seal bristles.

A magnetic speed sensor was positioned at the pulley end of the shaft to measure its rotational velocity. An optical speed sensor was positioned on the outer diameter of the brush seal to detect the speed of a small strip of reflective tape bonded to the outer circumference of the seal.

A video camera connected to a high magnification borescope was used to capture images at the bristle-rotor interface. The borescope was coupled to an electronic stroboscopic mechanism, which was activated by an external optical sensor that sensed the same reflective tape used by the optical speed indicator. Two additional video cameras were used along with a video mixer and a VCR to record a panoramic view of the brush seal and the two speed indicator meters. A Nikon 35mm SLR camera was used to capture, off-line, still pictures of the images recorded on videotape during the experiment.

The brush seal used for this analysis was designed by B\&CEA and manufactured by Cross Manufacturing Ltd. (Devizes, U.K.). Figure 3 shows a schematic of the brush seal and its dimensions. The brush contains 10 rows of 0.004 in. diameter bristles made of Haynes 25. The bristles are inclined at $30^{\circ}$ in the direction of the rotor rotation. The side plates are approximately $0.1 \mathrm{in}$. thick and have inner and outer diameters of 2.88 in. and 3.7 in., respectively. The outer ends of the bristles make up the inner diameter of the seal at 2.78 in. The design of the brush seal came from analytic modeling of the bristle behavior, which will be described in the analytical model section of this paper. 


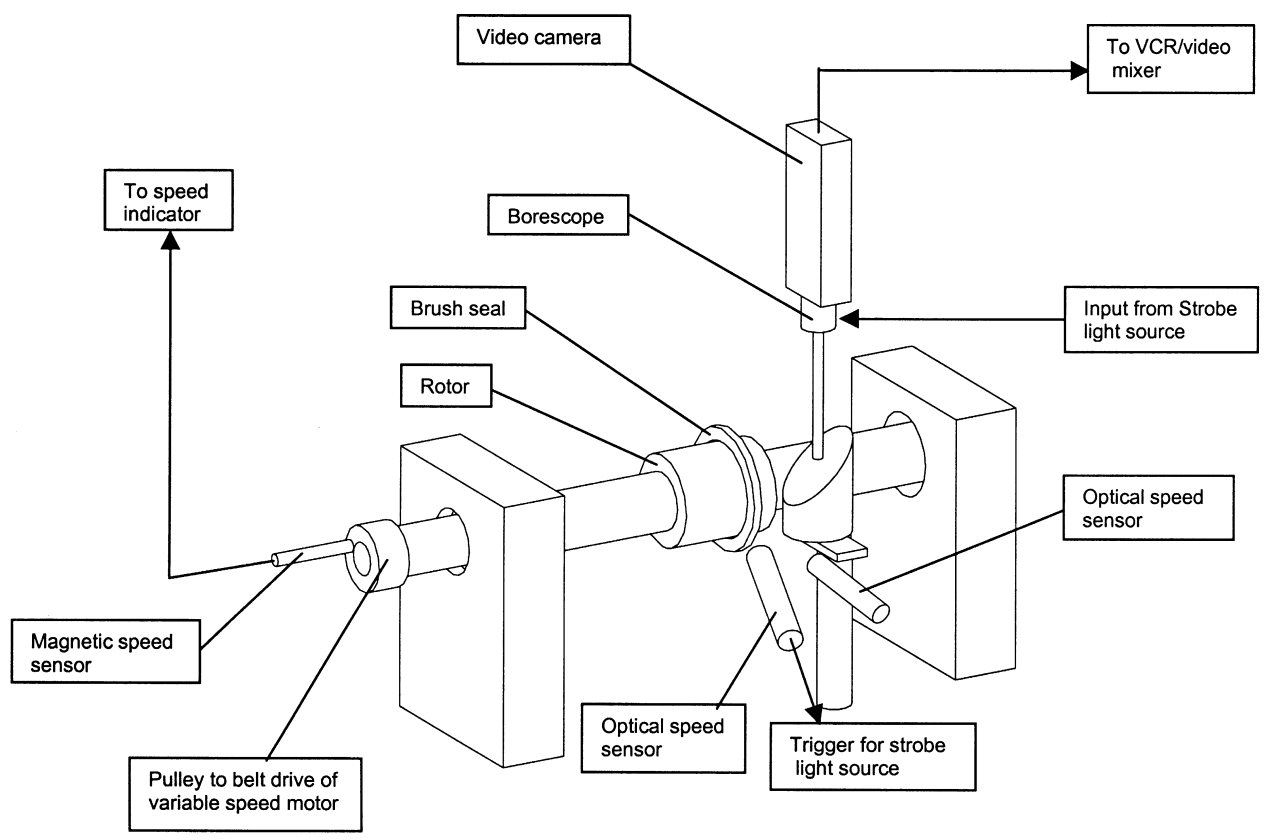

FIGURE 2 Experimental apparatus schematic.
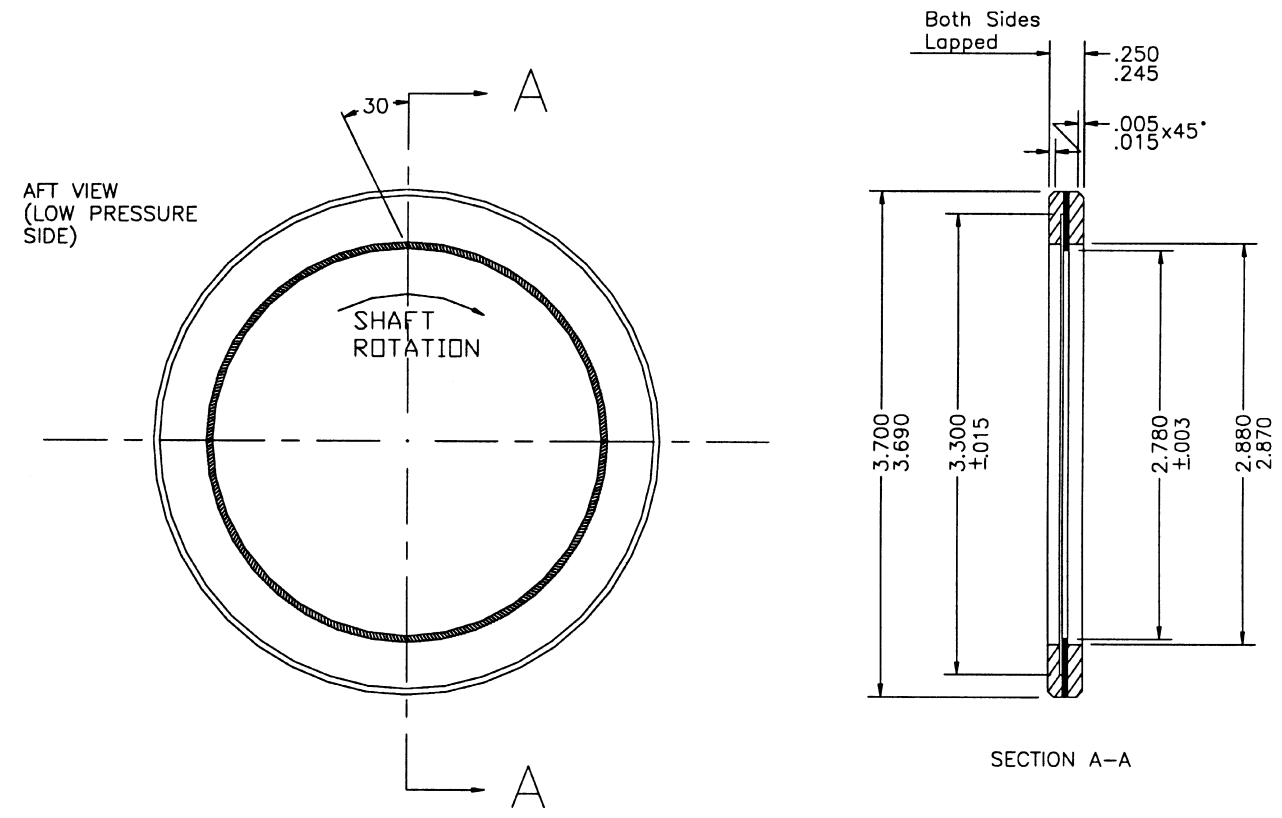

FIGURE 3 Brush seal.

\section{EXPERIMENTAL PROCEDURE}

The brush seal was centered on a 2.788 in. diameter section of the rotor, producing 0.004 in. of radial preload. The optical speed sensors were positioned to face the outer circumference of the brush seal. A $0.125 \times 0.5$ in. strip of reflective tape had been bonded on the outside diameter of the brush seal and served as the trigger for the optical sensors. One of the optical sensors measured the speed of the brush seal. The second optical sensor triggered the light source to flash at the rotational speed of the brush seal, allowing the capture of a "frozen" image of the bristle-shaft 
interface through the borescope. The magnetic speed sensor was positioned to face a key at the pulley end of the shaft.

Three video cameras were used during the experiment. The first camera was attached to the borescope and positioned vertically over a $45^{\circ}$ angled mirror, see Figure 2 . The mirror allowed the camera to look in the axial direction, along the shaft, at the bristle-rotor interface. The borescope end was placed at a circumferential position of about nine o'clock in the brush seal plane. The second video camera was positioned to take a panoramic image of the backside of the brush seal. This camera was also utilized to view any strobed light of the borescope escaping through the bristle pack. Penetration of such light was a clear indication of bristle lift-off from the rotor. The third camera was positioned on the speed indicator meters to view the speeds of both the rotor and the brush seal simultaneously with the other two views. A Videonics digital mixer was used to incorporate two of the three images on the same picture. This allowed the speeds of the brush seal and rotor to be captured interchangeably with the panoramic and magnified views of the brush seal.

After the system had sufficient time to warm up, the rotor was brought to $1,000 \mathrm{rpm}$ and the VCR began recording images. Images of the bristle-rotor interface were recorded, with and without the speed meters, and the panoramic view of the backside of the brush seal with the speed meters. This procedure was repeated for speeds up to $4,000 \mathrm{rpm}$, in increments of $1,000 \mathrm{rpm}$. The rotor speed was then increased in increments of $200 \mathrm{rpm}$ from 4,000 to $11,000 \mathrm{rpm}$, with the same sets of images being recorded.

For visual characterization of the transient behavior of the brush seal, both the bristle-rotor interface and the back plane of the brush were recorded concomitantly. The rotor was brought up from 0 to $11,000 \mathrm{rpm}$ in 27 seconds and then down from 11,000 to $0 \mathrm{rpm}$ in 35 seconds.

\section{ANALYTICAL MODEL OF BRISTLE DEFLECTION}

The design process of the brush seal involved parametric calculations using the geometric characteristics and material properties of the bristles. The calculations allowed the determination of the highest rotational speed at which the bristles would begin to lift off the rotor for a given bristle geometry. These properties included: a) total length of the bristles; b) length of the back and front plate; c) diameter of the bristles; d) lay angle of the bristles; e) bristle preload; f) bending stress of the bristles.

The eventually chosen geometric parameters were designed to ensure that bristle lift-off would be delayed as much as possible. This is necessary in order to assure that the brush speed tracks the shaft speed as closely as possible. The present analysis considers only two forces contributing to the bristle deflection; bristle pre-load (interference of the inner diameter of the brush seal over the outer diameter of the rotor), and centrifugal force, due to the rotation. Other influences, such as windage of the rotor and bristle packing have not been included in this analysis.

Consider the forces acting on a single bristle of length $\ell$, diameter $\mathrm{d}$, under a preload $\mathrm{P}$, lay angle $\theta$, and $\mathrm{a}$ rotational speed $\omega$. The preload is the force applied by the rotor onto the bristle, as the O.D. of the rotor pushes the end of the bristle outward radially from its center. This is shown schematically in Figure 4 . The deflection, $\delta_{\mathrm{P}}$, due to preload, $\mathrm{P}$, is given by:

$$
\delta_{P}=\frac{P l^{3}}{3 E I} \quad \text { where } \quad I=\frac{\pi d^{4}}{64}
$$

The deflection, $\delta_{\mathrm{w}}$, due to centrifugal load, $\mathrm{q}$, (assuming a uniform load) is given by:

$$
\delta_{\mathrm{W}}=\frac{\mathrm{q}^{4}}{8 \mathrm{EI}}=\frac{w l^{3} \sin \theta}{8 E I}
$$

where $q=\frac{w \sin \theta}{l}, w=m r \omega^{2}, I=\frac{\pi d^{4}}{64}$ and $m$ is the mass of the bristle.

Next, we analyzed what happens to the bristle as it begins to rotate with the shaft. The bristle will remain in a constant state of deflection, $\delta$, developed from the preload, from $\omega=0$ until $\omega=\omega^{*}$, where $\omega^{*}$ is the speed at which the

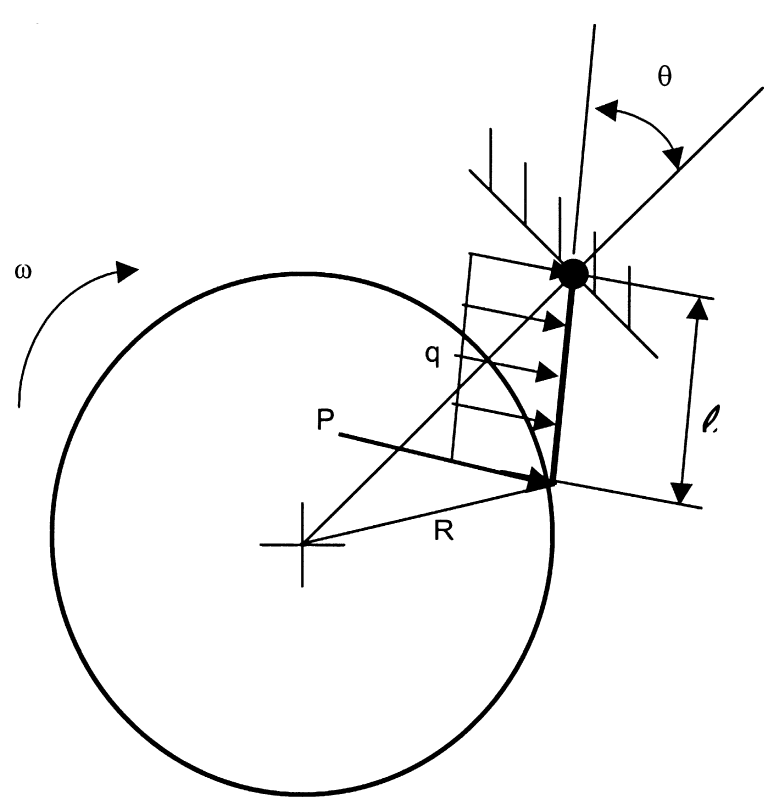

FIGURE 4 Single bristle under preload P and speed. 
centrifugal load begins to lift the bristle off the rotor. With this in mind, we examined three cases:

I. $\omega=0: \delta=\delta_{\mathrm{P} 1}+\delta_{\mathrm{w} 1}$, but $\delta_{\mathrm{w} 1}=0$. Thus, $\delta=\delta_{\mathrm{P} 1}$.

II. $0<\omega<\omega^{*}: \delta=\delta_{\mathrm{P} 2}+\delta_{\mathrm{w} 2}$. Thus, $\delta_{\mathrm{P} 2}<\delta_{\mathrm{P} 1}$ and $\delta_{\mathrm{w} 2}>0$.

III. $\omega=\omega^{*}: \delta=\delta_{\mathrm{P} 3}+\delta_{\mathrm{w} 3}$, but $\delta_{\mathrm{P} 3}=0$. Thus, $\delta=\delta_{\mathrm{w} 3}$ and $\delta_{\mathrm{w} 3}>\delta_{\mathrm{w} 2}$

Looking at the problem from this point of view, we see that as speed increases, the preload force decreases, and the centrifugal force increases. Proceeding along this course, we are now interested to find what speeds are attainable for a given bristle geometry and preload at which the bristles begin to lift off the rotor.

Using these simple equations, the brush seal design was principally controlled by the rotational speed at which the circumferential force would overcome the bristle preload for various bristle geometries. At this point, the bristles would begin to lift off the rotor and, presumably, the brush seal would begin to slip on the circumference of the rotor.

\section{DISCUSSION OF RESULTS}

\section{Analytical Model}

Table I presents a parametric study for bristle design, based on previously mentioned equations, used in the design of the brush seal. The table presents values for bristle diameter (d), and length $(\mathbf{L})$, radius of the rotor $(\mathbf{R})$, rotational speed $(\omega)$, lay angle $(\theta)$, total deflection $(\delta$ - preload deflection at $0 \mathrm{rpm})$, deflection due to centrifugal force $\left(\delta_{\mathbf{w}}\right)$, deflection due to preload $\left(\delta_{\mathbf{p}}\right)$, and total bending stress $(\sigma)$. Rotational speeds were increased from $0 \mathrm{rpm}$ until the centrifugal deflection equaled the preload deflection at $0 \mathrm{rpm}$. This is the speed at which the bristle would begin to lift off the rotor. Bristle diameters from 0.001 to 0.005 in., bristle lengths of 0.4 to 0.15 , preload deflections of 0.015 to 0.002 in., and lay angles of $20^{\circ}$ to $60^{\circ}$ were examined. The numbers shown in the table represent some of the more physically realistic geometries.

Preliminary testing for bristle lift speed on some previously acquired brush seals, when compared to the model's predictions, showed the analytical results to be conservative. We felt at this point that the effects of bristle packing (packing not considered) were responsible for the model's early lift-off predictions. The results from the bristle deflection model and discussions with the brush seal manufacturer led to the brush seal design previously shown in Figure 3. The single brush consists of ten rows of 0.004 in. diameter bristles, $0.31 \mathrm{in}$. long, at angle of $30^{\circ}$. The model predicted bristle lift-off after 4,155 rpm, as shown in the last entry of Table I. The brush seal, being positioned on the $2.788 \mathrm{in}$. diameter of the rotor, produced a radial pre-load deflection of 0.004 in.

\section{Experimental Results}

Figures 5 and 6 show a series of video images collected during the experiment. Figure 5 shows the bristle-rotor interface at rotational speeds of 8,9 , and $10,000 \mathrm{rpm}$. The bristles began to separate from the rotor around 5,000 rpm, after which the separation gap continued to grow. The gaps that are shown in the figures, between the rotor O.D. and the brush seal I.D., are about half the size that they appear to be. The rotor surface reflects the bristle ends so that a mirror image appears at the bristle-rotor interface. This reflection is seen because $45^{\circ}$ mirror was rotated slightly outside the O.D. of the rotor surface in order to bring more light to the bristle-rotor interface. The speeds of both the rotor and brush seal are shown in all the figures. The brush kept up with the rotor to the maximum tested rotor speed of $11,000 \mathrm{rpm}$. The theory developed from the analytical model suggested that as the bristles lifted off the rotor, the brush seal would begin to slip and thus, rotate at a slower angular velocity than the rotor. The experiments showed that as the rotational speed of the brush seal increased, a critical speed $\omega^{*}$ was reached, after which, the bristles began to lift off the rotor. However, the brush seal did not, as our theory assumed, begin to slip after the critical speed was reached or surpassed. Figure 5 shows the bristle-rotor interface at speeds of 8,9 and 10,000 rpm, well after bristle lift off had occurred, with no speed differential occurring between the rotor and the brush seal. It is apparent that an aerodynamic layer is developed between the O.D. of the rotor and the I.D. of the brush seal. This layer provides

TABLE I Bristle design parameters vs. speed

\begin{tabular}{lcccccccc}
\hline $\boldsymbol{d}$ (in) & $\boldsymbol{L}(\mathrm{in})$ & $\boldsymbol{R}(\mathrm{in})$ & $\omega$ & $\theta$ & $\delta($ in $)$ & $\delta_{\boldsymbol{w}}(\mathrm{in})$ & $\delta_{\boldsymbol{p}}($ in $)$ & $\sigma(\mathrm{psi})$ \\
\hline 0.004 & 0.3 & 1.4 & 7010 & 30 & 0.01 & 0.00999 & $9.59 \mathrm{E}-06$ & 26660.27 \\
0.004 & 0.3 & 1.4 & 4960 & 30 & 0.005 & 0.005002 & $-1.6 \mathrm{E}-06$ & 13334.41 \\
0.004 & 0.25 & 1.4 & 10170 & 30 & 0.01 & 0.010005 & $-4.9 \mathrm{E}-06$ & 38404.73 \\
0.004 & 0.25 & 1.4 & 7190 & 30 & 0.005 & 0.005001 & $-6.9 \mathrm{E}-07$ & 19200.66 \\
0.004 & 0.2 & 1.4 & 16000 & 30 & 0.01 & 0.010004 & $-4 \mathrm{E}-06$ & 60006.07 \\
0.004 & 0.2 & 1.4 & 11310 & 30 & 0.005 & 0.004999 & $1.25 \mathrm{E}-06$ & 29998.12 \\
0.004 & 0.31 & 1.394 & 4155 & 30 & 0.004 & 0.003997 & $3.39 \mathrm{E}-06$ & 10617.44 \\
\hline
\end{tabular}




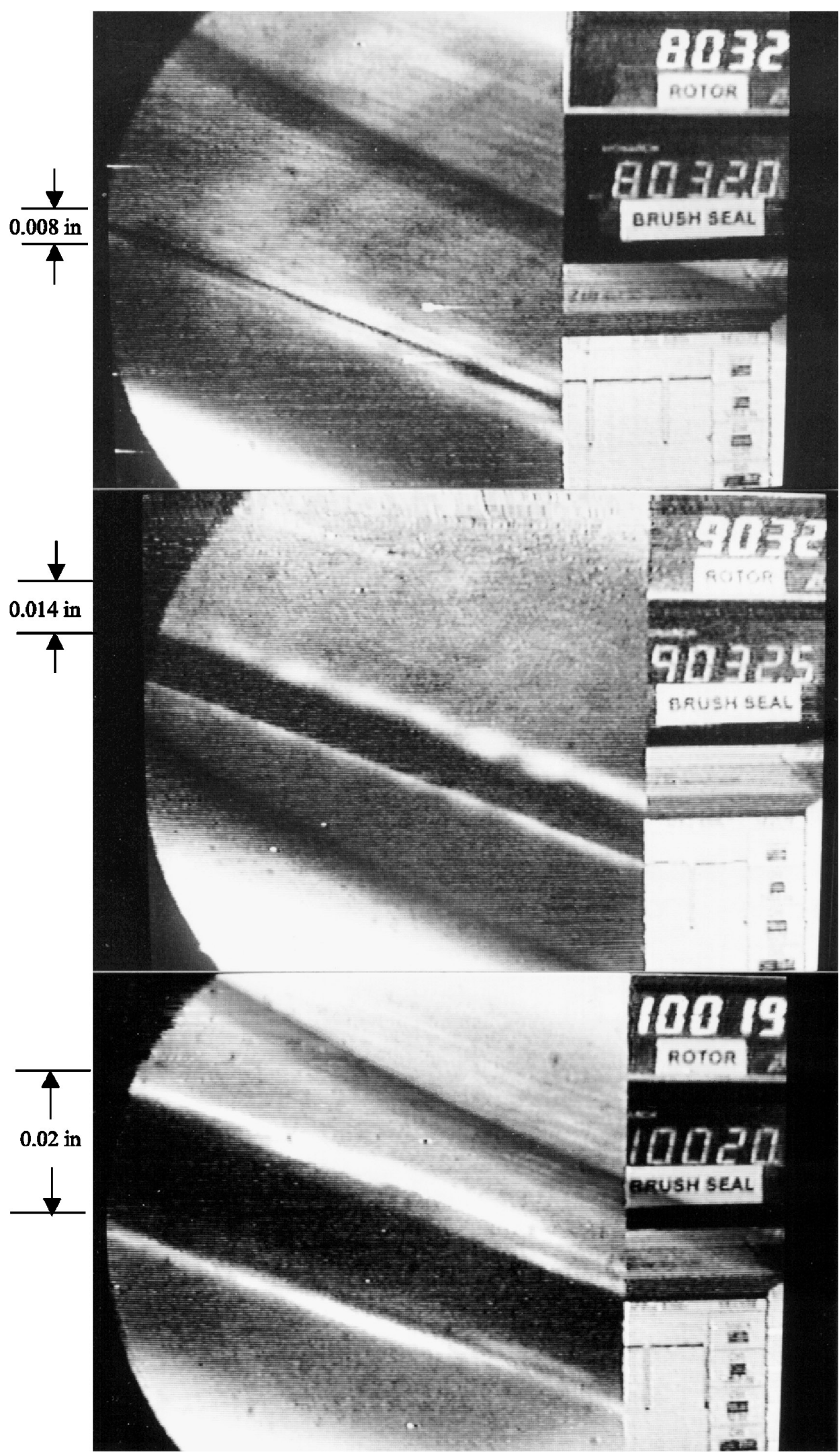

FIGURE 5 Bristle-rotor interface at 8, 9, and 10,000. 


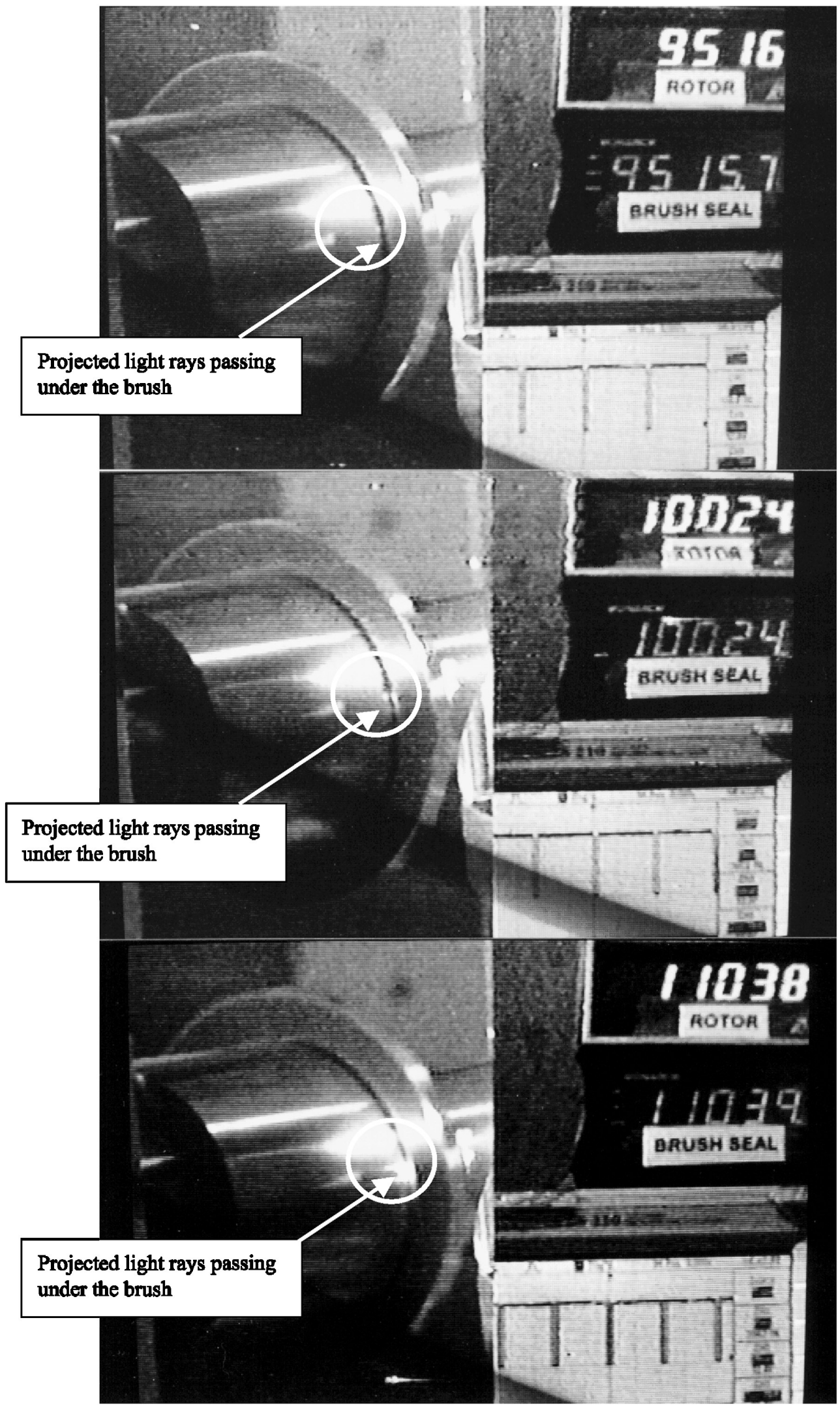

FIGURE 6 Backside of brush seal at 9, 10, and 11,000. 
enough friction between the rotor and the bristles such that the rotational speeds of each remain synchronous. The circumferential momentum of the vortex layer is very significant since it can potentially provide sealing capabilities with no direct contact between the rotor and the brush. This phenomenon occurred throughout the experiments, even at the maximum tested speed of $11,000 \mathrm{rpm}$.

Figure 6 shows a panoramic view of the backside of the brush seal. After a rotational speed of $9,500 \mathrm{rpm}$ was reached, the light being emitted from the strobe light source can be seen coming through the bristle pack from the backside of the brush seal. This is clearly demonstrated from the series of photos in Figure 6. The light (encircled in white) is shown to grow with the rotor (brush seal) speed, at the bristle-rotor interface, at the three o'clock position on the brush seal back face. Although not shown in any of the figures, the clearance between the inner diameter of the brush seal and the outer diameter of the rotor was visually observed around the entire circumference of the rotor from speeds above $8,000 \mathrm{rpm}$. The relative speeds of both the rotor and brush seal are shown not to vary up through $11,000 \mathrm{rpm}$. The radial clearance between the rotor O.D. and the brush seal I.D. at 10,000 rpm was measured to be approximately 0.01 inches.

The transient behavior of the brush seal was observed and recorded on video. This was accomplished by bringing the rotor rapidly up to the maximum operating speed of $11,000 \mathrm{rpm}$ from rest, and then shutting down the motor or bringing the speed down rapidly with the motor controller. The same clearances from bristle deflection were observed as when acquired through gradual increase or decrease of speed. The panoramic view of the brush seal showed no signs of instability in any of the tests performed. Inspection of the brush seal showed no damage to the bristles due to ramp-up or shut down-speed changes. This result is very important, in that, it was previously believed that rapid decreases in rotor speed could damage the bristles because the relative motion of the rotor will be against the bristle lay angle.

\section{Experimental-Analytical Comparison}

Table II shows a table of centrifugal deflections versus speed based on the analytical model and measurements of the captured images. The model predicted bristle liftoff after $4,155 \mathrm{rpm}$. This was fairly close to experimental observations. The bristles were observed to lift around 4,500 to

TABLE II Centrifugal deflection vs. speed

\begin{tabular}{lccc}
\hline$\omega(\mathrm{rpm})$ & $\delta_{W m}(\mathrm{in})[$ model $]$ & $\delta_{W e}($ in $)$ [experimental] & $\delta_{W m} / \delta_{W e}($ in $)$ \\
\hline 8000 & 0.015 & 0.004 & 3.75 \\
9000 & 0.019 & 0.007 & 2.7 \\
10000 & 0.023 & 0.011 & 2.1 \\
\hline
\end{tabular}

$5,000 \mathrm{rpm}$. The centrifugal deflections measured from the experimental images and those predicted by the model, as shown in Table II, do not correspond. We believe the large discrepancies in the predicted bristle deflections are due to the effects of bristle packing, which was not incorporated in the model. The model was based on a single bristle and applied to more than 190,000 bristles (10 rows at 2170 bristles per inch of bore circumference, nominal).

\section{CONCLUSIONS}

The experiments showed that the brush seal will reach a critical speed, after which, the bristles will begin to lift off the rotor. The experiments also provided the unexpected result of the bristles being entrained by an aerodynamic layer between the rotor and the bristle tips long after liftoff has occurred. The aerodynamic layer provided enough circumferential momentum to keep the brush seal rotating at the same speed as the rotor up to the maximum operating speed of $11,000 \mathrm{rpm}$. The numerical model provided some insight for the qualitative behavior of a rotating brush seal but did not correspond quantitatively to experimental results. It is believed that the effects of bristle packing and windage of the rotor must be included for a more realistic model to be developed.

\section{REFERENCES}

Atkinson, E. and Bristol, B. (1992) Effects of Material Choices on Brush Seal Performance, Lubrication Engineering, Vol. 48, pp. 740-746.

Braun, M. J., Hendricks, R. C. and Canacci, V. (1990) Non-Intrusive Qualitative and Quantitative Flow Characterization and Bulk Flow Model for Brush Seals, Proceedings of the Japan International Tribology Conference, Vol. III, pp. 1611-1616, Nagoya, Japan.

Braun, M. J. and Kudriavtsev, V. V. (1995) Hybrid Floating Brush Seal, SBIR Phase-I, Final Report, June.

Braun, M. J. and Choy, F. K. (1996) Hybrid Floating Brush Seal, Patent Pending.

Chupp, R. E. and Dowler, C. A. (1991) Performance Characteristics of Brush Seals for Limited Life Engines, 36 ${ }^{\text {th }}$ ASME Gas Turbine Conference, Orlando, Florida, paper no. 91-GT-281.

Ferguson, J. G. (1988) Brushes as High Performance Gas Turbine Seals, $33^{\text {rd }}$ ASME Gas Turbine Conference, Amsterdam, The Netherlands, paper no. 88-GT-182.

Forry, J. M. (1993) High Temperature Brush Seals and High Pressure Ratio Swept Fan Program, Vol. I, High Temperature Brush Seals, Wright Laboratory Technical Report no. WL-TR-94-2007.

Hendricks, R. C., Schlumberger, J., Braun, M. J, Choy, F. K. and Mullen, R. L. (1991) A Bulk Flow Model of a Brush Seal System, Proceedings of the 1991 ASME International Gas Turbine and Aeroengine Congress and Exposition, Paper \#91-GT-325, Orlando, Florida, June 3-6.

Hendricks, R. C., Griffen, T. A., Bobula, G. A., Bill, R. C. and Howe, H. W. (1992) Integrity Testing of Brush Seal in a T-700 Engine, NASA Conference Publication 10124, NASA Lewis Research Center Seals Workshop, Cleveland, Ohio, pp. 117-138.

Proctor, M. P., Walker, J. F., Perkins, H. D., Hoopes, J. F. and Williamson, G. S. (1996) Brush Seals for Cryogenic Applications: Performance, Stage Effects, and Preliminary Wear Results in $\mathbf{L N}_{2}$ and $\mathrm{LH}_{2}$, NASA Technical Paper no. 3536 . 

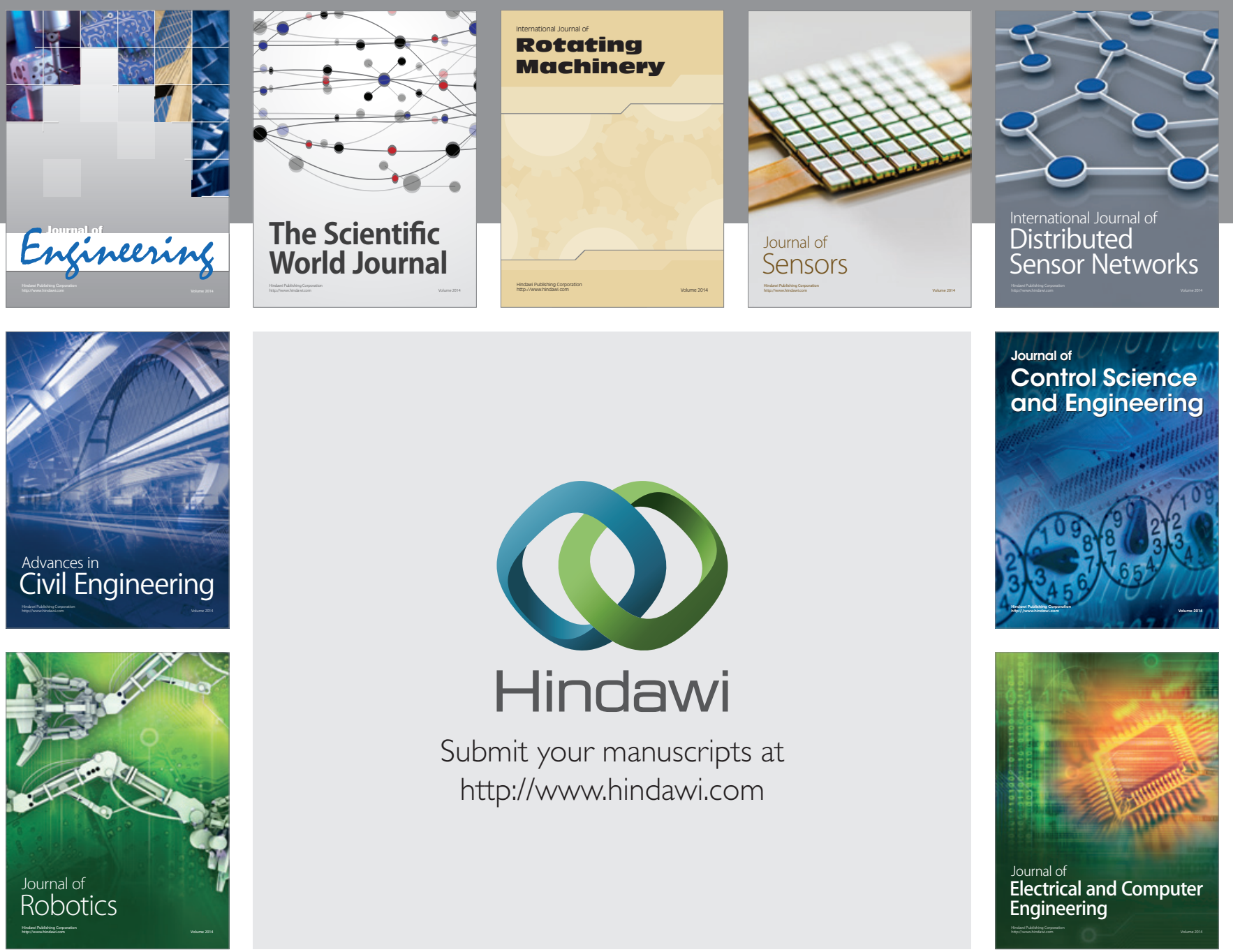

Submit your manuscripts at

http://www.hindawi.com
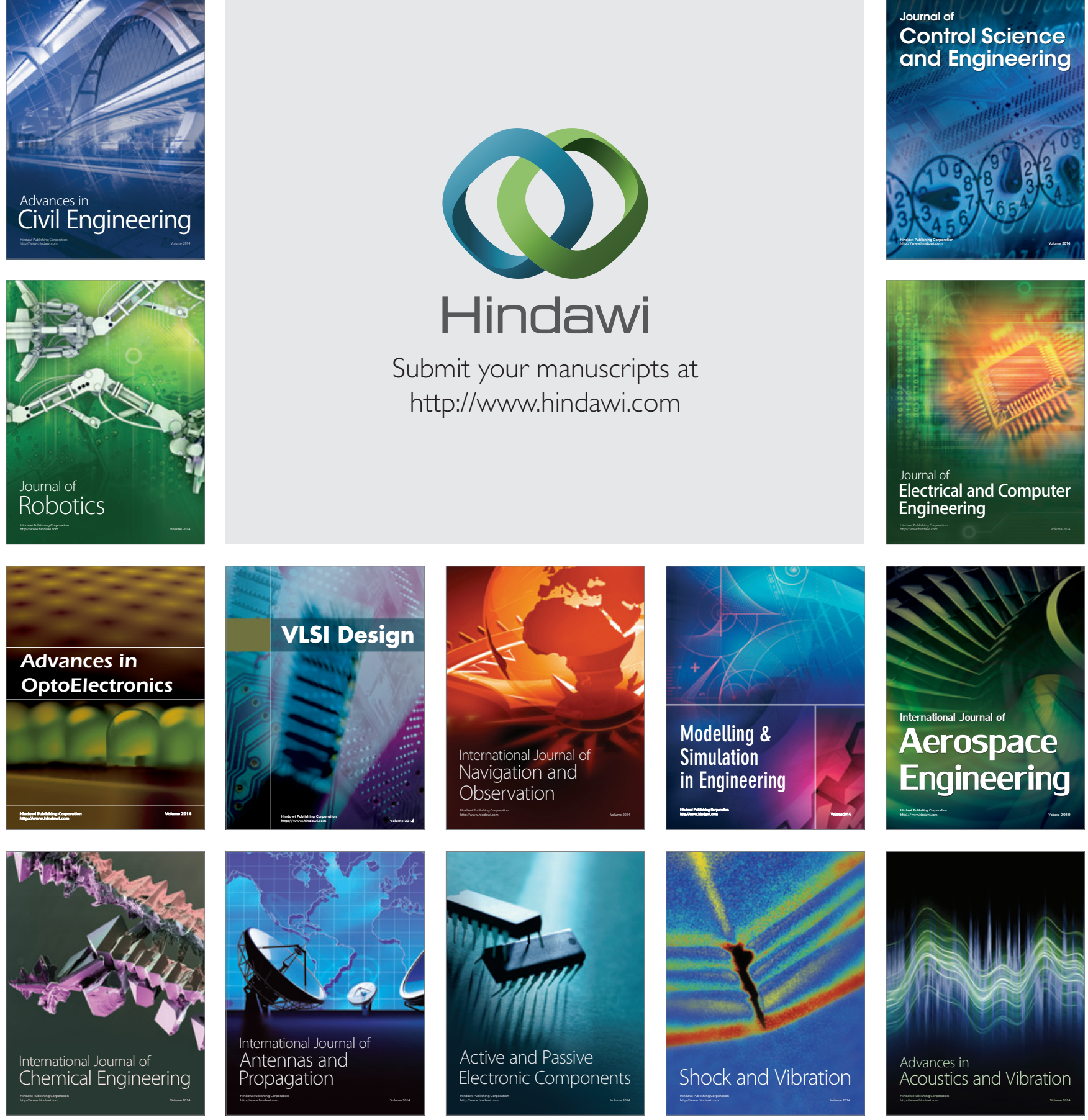